\title{
EFEKTIFITAS PENGGUNAAN MEDIA LEAFLET TERHADAP PENINGKATAN PENGETAHUAN TENTANG NARKOBA DI SMPN 5 BANJARBARU
}

\author{
Pusparina, Iis $^{1}$; Maria, Insana ${ }^{2}$; Anggraini, Danti Tia ${ }^{3}$ \\ ${ }^{1,3}$ Dosen Sekola Tinggi Ilmu Kesehatan Intan Martapura \\ ${ }^{2}$ Mahasiswa Sekolah Tinggi Ilmu Kesehatan Intan Martapura \\ Email: maria.insana82@gmail.com
}

\begin{abstract}
INTISARI
Latar Belakang: Narkoba dapat menimbulkan ketergantungan (adiksi) fisik dan psikologis. Penyalahgunaan narkoba tidak hanya terjadi usia dewasa tetapi juga pada anak sekolah, kurangnya pengetahuan siswa dalam penyalahgunaan narkoba dapat disebabkan kurangnya informasi seperti penyulungan tentang narkoba, media penyuluhan yang dapat digunakan salah satunya media leaflet.

Tujuan: Mengetahui pengaruh media leaflet untuk peningkatan pengetahuan remaja tentang narkoba.

Metode: Desain Penelitian yang digunakan adalah Quasy Eksprerimental dengan instrument kuesioner. Populasi seluruh siswa SMPN 5 Banjarbaru sebanyak 305 siswa menggunakan Purposive Sampling dengan jumlah sampel 76 responden. Data dianalisis menggunakan uji Wilcoxon Signed Ranks Test.

Hasil: Penelitian ini menunjukkan bahwa variable pengetahuan yang diukur dengan menggunakan metode pretest dan posttest pada responden menghasilkan peningkatan pengetahuan setelah diberikan media leaflet dengan $p$-value sig-0,000 $<0,05$ yang berarti ada pengaruh media leaflet terhadap pengetahuan remaja tentang narkoba di SMPN 5 Banjarbaru.

Saran: Mengoptimalkan pengetahuan responden tentang bahaya narkoba agar dimasa akan datang responden bisa mengantisipasi diri dan mencegah agar terhindar dari narkoba yang sangat berbahaya.
\end{abstract}

Kata Kunci : Leaflet, Pengetahuan, Narkoba 


\section{PENDAHULUAN}

Narkoba (singkatan dari Narkotika, Psikotropika dan Bahan Adiktif berbahaya lainnya) adalah bahan/zat yang jika dimasukan dalam tubuh manusia, baik secara oral/diminum, dihirup, maupun disuntikan, dapat mengubah pikiran, suasana hati atau perasaan, dan perilaku seseorang. Narkoba dapat menimbulkan ketergantungan (adiksi) fisik dan psikologis. Penyalahgunaan narkotika dan obat-obatan terlarang di kalangan generasi muda dewasa terus meningkat sehingga membahayakan keberlangsungan hidup bangsa ini di kemudian hari.

Pemuda sebagai generasi yang diharapkan menjadi penerus bangsa, semakin hari semakin rapuh digerogoti zat-zat adiktif penghancur syaraf. Sehingga pemuda tersebut tidak dapat berpikir jernih. Akibatnya, generasi harapan bangsa yang tangguh dan cerdas hanya akan tinggal kenangan. Sasaran dari penyebaran narkoba ini adalah kaum muda atau remaja. Kalau dirata-ratakan, usia sasaran narkoba ini adalah usia pelajar, yaitu berkisar umur 11 sampai 24 tahun. Hal tersebut mengindikasikan bahwa bahaya narkoba sewaktu-waktu dapat mengincar anak didik kita kapan saja (Purnama, Arif Putra, 2013).

Kelompok usia remaja cenderung memiliki sifat penasaran yang tinggi sehingga banyak remaja yang ingin coba-coba. Dapat dikatakan bahwa pada saat ini Indonesia sedang dilanda masalah penyalahgunaan nartkotika yang sangat serius karena mengancam generasi muda. Remaja merupakan golongan yang rentan terhadap penyalahgunaan narkoba karena selain memiliki sifat dinamis, energik, selalu ingin mencoba mereka juga mudah terpengaruh oleh lingkungan sekitar dan mudah putus asa sehingga mudah jatuh pada masalah penyalahgunaan narkotika. (Suryono, 2012)

Komisi Perlindungan Anak Indonesia (KPAI) tahun 2018 mencatat dari 87 juta populasi anak di Indonesia, sebanyak $6,9 \%$ di antaranya menjadi pecandu narkoba. Daerah Kalimantan Selatan tercatat 55.598 orang, dimana $27 \%$ pengguna narkoba merupakan remaja. Berdasarkan kelompok umur terdapat 74 orang pengguna merupakan remaja berusia $15-19$ tahun. Berdasarkan tingkat pendidikan pada tahun 2017 terdapat 25 orang tamat SD sederajat, 52 orang tamat SMP sederajat diantaranya SMPN 5 Banjarbaru, 90 orang tamat SMA sederajat. Berdasarkan data pengguna narkoba berjenis kelamin laki - laki sebanyak 147 orang dan perempuan 28 orang. (BNN Prov Kal-Sel, 2018)

Penyuluhan yang akan di berikan kepada Remaja dapat dilaksanakan oleh tenaga kesehatan salah satunya adalah perawat, dengan penyuluhan yang di berikan dapat meningkatkan pengetahuan baik pada remaja, keluarga dan seluruh masyarakat (Insana Maria, 2018). Pengetahuan yang di dapatkan mampu meningkatkan kepercayaan diri bagi remaja untuk mengenal permasalahan yang ada untuk dicarikan jalan keluarnya (Insana Maria. 2019), berdasarkan latar belakang di atas, maka peneliti tertarik untuk mengidentifikasi penggunaan "Media Leaflet terhadap Pengetahuan Remaja tentang Narkoba di SMPN 5 Banjarbaru“.

\section{METODE}

Metode penelitian yang digunakan dalam penelitian ini adalah eksperimen semu (quasy eksperimen). Rancangan ini berupaya untuk mengungkapkan hubungan sebab akibat dengan cara melibatkan kelompok kontrol disamping kelompok eksperimental. Tapi, 
pemilihan kedua kelompok ini tidak menggunakan teknik acak. Rancangan ini biasanya menggunakan kelompok subjek yang telah terbentuk secara wajar (teknik rumpun), sehingga sejak awal bisa saja kedua kelompok subjek telah memiliki karakteristik yang berbeda. Jumlah populasi untuk penelitian ini adalah 305 siswa, sedangkan jumlah sampel adalah 76 responden. Teknik sampling yang digunakan adalah dengan Purposive Sampling. Tempat penelitian dilakukan di SMPN 5 Banjarbaru dikarenakan dari data yang tercatat oleh BNNK Banjarbaru, pasien rehabilitasi yang ditangani mengalami peningkatan dan berada di sekitar SMPN. Proses penelitian tidak dilakukan dengan meminta sertifikat uji etik penelitian dikarenakan keterbatasan waktu dari peneliti sehingga dalam kegiatan langsung dilaksanakan penelitian. Tapi, peneliti tetap berpegang teguh pada prinsip-prinsip etik yang berlaku.

\section{HASIL PENELITIAN}

Tabel 1. Distribusi Frekuensi Data Kareakteristik Umum Responden kelas VIII di SMPN 5 Banjarbaru Tahun 2019

\begin{tabular}{cccc}
\hline No & Variabel & Frekuensi & $\%$ \\
\hline 1. & Jenis Kelamin & & \\
\hline & Laki - laki & 33 & $43,4 \%$ \\
\hline & Perempuan & 43 & $56,6 \%$ \\
\hline 2. & Umur & & \\
\hline & 14 Tahun & 43 & $56,6 \%$ \\
\hline & 15 Tahun & 33 & $43,4 \%$ \\
\hline & Total & 76 & $100 \%$
\end{tabular}

Sumber : Data primer yang sudah diolah (2019)

Distribusi frekwensi pada tabel 1 diatas menunjukkan bahwa responden mempunyai karakteristik umum yaitu berumur 14 Tahun sebanyak 43 responden $(56,6 \%)$, jenis kelamin perempuan sebanyak 43 responden $(56,6 \%)$.
Tabel 2. Distribusi Frekuensi Parameter Pengetahuan Responden tentang Bahaya Narkoba Tahun 2019

\begin{tabular}{cccccc}
\hline \multirow{2}{*}{ Ko } & Kategori & \multicolumn{2}{c}{ Pretest } & \multicolumn{2}{c}{ Postest } \\
\cline { 3 - 6 } & & Frekuensi & $\%$ & Frekuensi & $\%$ \\
\hline $\mathbf{1}$ & Baik & 72 & $94,7 \%$ & 76 & $100 \%$ \\
\hline $\mathbf{2}$ & Cukup & 4 & $5,3 \%$ & 0 & $0 \%$ \\
\hline \multicolumn{2}{c}{ Total } & 76 & $100 \%$ & 76 & $100 \%$
\end{tabular}

Sumber : Data primer yang sudah diolah (2019)

Berdasarkan tabel 2 di atas dapat dilihat bahwa Tingkat Pengetahuan Tentang Bahaya Narkoba, secara umum sebelum menggunakan media leaflet pengetahuan responden mayoritas dikategorikan berpengetahuan baik 72 responden $(94,7 \%)$, setelah menggunakan media leaflet mayoritas dikategorikan berpengetahuan baik sebanyak 76 responden $(100 \%)$.

Tabel 3. Distribusi Frekuensi Katergori Pengetahuan tentang Bahaya Narkoba Sebelum Diberikan Media Leaflet Tahun 2019

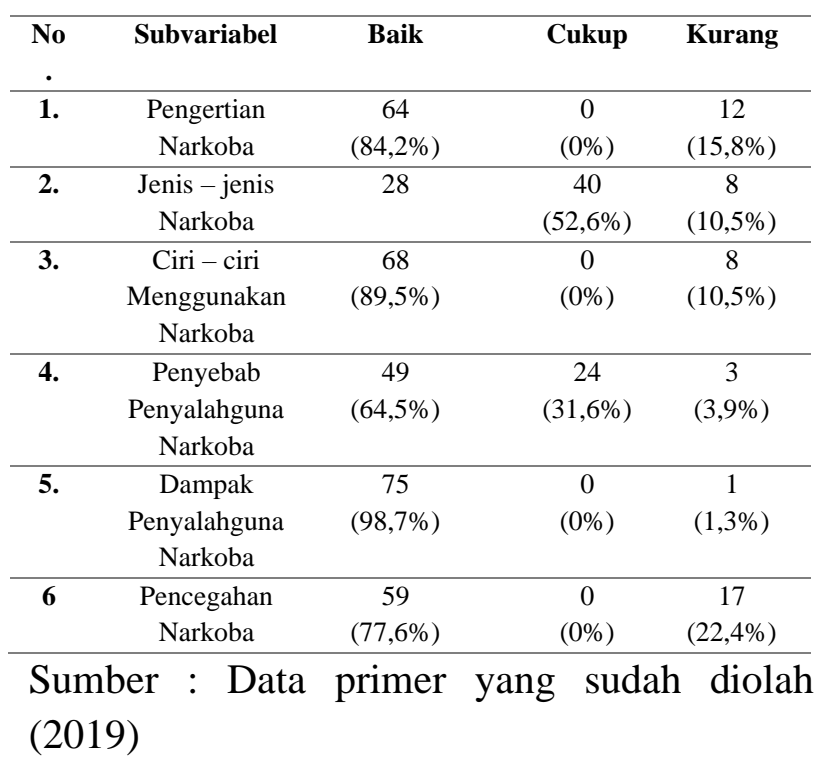

Berdasarkan tabel 3 diatas dapat dilihat bahwa mayoritas pengetahuan remaja dominan dikategorikan baik seperti Dampak 
Penyalahguna Narkoba sebanyak 75 responden $(98,7 \%)$.

Tabel 4. Distribusi Frekuensi Katergori Pengetahuan Tentang Bahaya Narkoba Sesudah Diberikan Media Leaflet Tahun 2019

\begin{tabular}{|c|c|c|c|c|}
\hline No. & Subvariabel & Baik & Cukup & Kurang \\
\hline 1. & $\begin{array}{c}\text { Pengertian } \\
\text { Narkoba }\end{array}$ & $\begin{array}{c}76 \\
(100 \%)\end{array}$ & $\begin{array}{c}0 \\
(0 \%)\end{array}$ & $\begin{array}{c}0 \\
0 \%)\end{array}$ \\
\hline 2. & $\begin{array}{c}\text { Jenis - jenis } \\
\text { Narkoba }\end{array}$ & $\begin{array}{c}53 \\
(69,7 \%)\end{array}$ & $\begin{array}{c}23 \\
(30,3 \%)\end{array}$ & $\begin{array}{c}0 \\
(0 \%)\end{array}$ \\
\hline 3. & $\begin{array}{c}\text { Ciri-ciri } \\
\text { Menggunakan } \\
\text { Narkoba }\end{array}$ & $\begin{array}{c}74 \\
(97,4 \%)\end{array}$ & $\begin{array}{c}0 \\
(0 \%)\end{array}$ & $\begin{array}{c}2 \\
(2,6 \%)\end{array}$ \\
\hline 4. & $\begin{array}{c}\text { Penyebab } \\
\text { Penyalahguna } \\
\text { Narkoba }\end{array}$ & $\begin{array}{c}64 \\
(84,2 \%)\end{array}$ & $\begin{array}{c}12 \\
(15,8 \%)\end{array}$ & $\begin{array}{c}0 \\
(0 \%)\end{array}$ \\
\hline 5. & $\begin{array}{c}\text { Dampak } \\
\text { Penyalahguna } \\
\text { Narkoba }\end{array}$ & $\begin{array}{c}76 \\
(100 \%)\end{array}$ & $\begin{array}{c}0 \\
(0 \%)\end{array}$ & $\begin{array}{c}0 \\
(0 \%)\end{array}$ \\
\hline 6 & $\begin{array}{c}\text { Pencegahan } \\
\text { Narkoba }\end{array}$ & $\begin{array}{c}72 \\
(94,7 \%)\end{array}$ & $\begin{array}{c}0 \\
(0 \%)\end{array}$ & $\begin{array}{c}4 \\
(5,3 \%)\end{array}$ \\
\hline
\end{tabular}

Sumber : Data primer yang sudah diolah (2019)

Berdasarkan tabel 4 diatas dapat dilihat bahwa mayoritas pengetahuan remaja dominan dikategorikan baik seperti Pengertian Narkoba sebanyak 76 responden (100\%), dan Dampak Penyalahguna Narkoba sebanyak 76 responden $(100 \%)$.

Tabel 5. Media Leaflet Terhadap Pengetahuan Remaja Tentang Bahaya Narkoba di SMPN 5 Banjarbaru Tahun 2019.

$\begin{array}{ccc}\text { Variabel } & \mathrm{P} & \mathrm{N} \\ \text { Pengetahuan pretest-posttest } & 0.00 & 76\end{array}$

Sumber : Data primer yang sudah diolah (2019).

\section{PEMBAHASAN}

Pada bagian ini akan dibahas mengenai hasil penelitian yang telah dilaksanakan yaitu Media Leftlet Terhadap Pengetahuan Tentang Narkoba di SMP Negeri 5 Banjarbaru. Berdasarkan data penelitian yang diperoleh hasil sebagai berikut :

1. Pengetahuan responden tentang Narkoba sebelum diberikan media leaflet di SMP Negeri 5 Banjarbaru

Hasil penelitian menunjukkan bahwa sebelum diberikan media leaflet pengetahuan responden tentang Bahaya Narkoba mayoritas dikategorikan berpengetahuan baik 72 responden $(94,7 \%)$ dan cukup 4 responden (5,3\%). Dari hasil distribusi jawaban sebelum diberikan leaflet parameter pengertian mayoritas berpengetahuan baik 64 responden $(84,2 \%)$, parameter jenis-jenis narkoba mayoritas berpengetahuan cukup 40 responden $(52,6 \%)$, parameter ciri-ciri menggunakan narkoba mayoritas berpengetahuan baik 68 responden $(89,5 \%)$, parameter penyebab penyalahgunaan narkoba mayoritas berpengetahuan baik 49 responden $(64,5 \%)$, parameter dampak menggunakan narkoba mayoritas berpengetahuan baik 75 responden $(98,1 \%)$, dan parameter pencegahan narkoba mayoritas berpengetahuan baik 59 responden $(77,6 \%)$. Hasil penelitian setiap parameter jawaban responden menunjukkan bahwa responden mayoritas pengetahuan baik tapi belum mencakup semua responden. Oleh karena itu, peneliti akan memberikan penyampaian penyuluhan menggunakan metode ceramah dengan leaflet tentang bahaya narkoba sehingga dapat membentuk komunikasi dua arah yang bagus antara peneliti dan responden mengenai apa yang 
belum paham dan rasa penasaran pada diri responden tentang pengetahuan narkoba.

Data dan penjabaran ini sesuai dengan pendapat Notoatmodjo (2015) yang menyatakan bahwa Informasi adalah keseluruhan makna yang dapat diartikan sebagai pemberitahuan kepada seseorang. Adanya informasi baru mengenai suatu hal memberikan landasan kognitif baru. Informasi yang cukup baik dari berbagai sumber seperti radio, televisi, majalah, koran, buku dan lain-lain dapat meningkatkan pengetahuan orang tersebut.

Hasil penelitian ini sejalan dengan penelitian yang dilakukan oleh Purba (2013) dimana hasil penelitiannya sebelum diberikan media leaflet menunjukkan bahwa terdapat pengetahuan remaja yang baik yaitu sebesar 15 remaja $(75 \%)$ dan pengetahuan cukup 5 remaja (25\%).

Pengetahuan adalah salah satu faktor predisposing terbentuknya perilaku pada remaja, yaitu faktor memotivasi. Pentingnya remaja mengetahui bahaya narkoba maka remaja akan tau cara pencegahannya agar menghindari sangat bahaya nya narkoba tersebut maka perlu dilakukan intervensi terhadap para remaja.

\section{Pengetahuan responden tentang}

\section{Narkoba sesudah diberikan media leaflet} di SMP Negeri 5 Banjarbaru

Berdasarkan hasil penelitian dapat diketahui bahwa setelah diberikan media leaflet pengetahuan responden tentang bahaya narkoba, mayoritas responden dikategorikan berpengetahuan baik sebanyak 76 responden (100\%). Dilihat dari tabel distribusi jawaban kuesioner pretest dan posttest sebelumnya bahwa memang terjadi peningkatan pengetahuan responden pada setiap parameter yang meliputi pengertian dengan mayoritas pengetahuan baik 76 responden (100\%), jenis-jenis mayoritas pengetahuan baik 53 responden $(69,7 \%)$, ciri-ciri mayoritas pengetahuan baik 74 responden $(97,4 \%)$, penyebab menggunakan narkoba mayoritas pengetahuan baik 64 responden $(84,2 \%)$, dampak menggunakan narkoba mayoritas pengetahuan baik 76 responden (100\%) dan pencegahan narkoba mayoritas pengetahuan baik 72 responden $(94,7 \%)$ setelah menggunakan media leaflet.

Data dan penjabaran tabel ini menunjukan bahwa media leaftlet dapat mempengaruhi pengetahuan. Bahaya menggunakan narkoba sangat penting diketahui oleh remaja. Ketika tidak mengetahui apa itu narkoba maka responden akan mengalami dampak yang sangat besar menggunakan narkoba. Hal ini sesuai dengan Notoadmojo (2015) bahwa pengetahuan merupakan hasil dari tahu dan terjadi setelah orang melakukan penginderaan terhadap suatu objek tertentu. Pada penelitian ini terlihat bahwa responden sudah mengetahui bahaya narkoba ketika sudah mengetahui bahaya narkoba maka responden akan menghindari narkoba karena sudah mengetahui bagaimana dampak yang akan terjadi bila menggunakannya. Hal ini sesuai dengan tingkatan aspek aplikasi pengetahuan.

Hasil penelitian ini sejalan dengan penelitian yang dilakukan Arif Putra Purnama (2016) bahwa pengetahuan yang dimiliki menjadi baik sebanyak 11 orang (55\%) dan pengetahuan cukup sebanyak 9 orang (45\%). Dari setiap kuesioner penelitian terjadi peningkatan setiap aspek kisi-kisi pengetahuan yang diberikan kepada responden.

Hal ini sesuai dengan proses perilaku tahu yang dikemukakan oleh Notoadmojo (2015) selain adanya pemberian intervensi, sebagian besar responden dalam tahap remaja yang 
memiliki kemampuan menyerap informasi baik sehingga menyebabkan pengetahuan yang baik. Semua itu tergantung dari diri responden semakin baik daya ingatnya pengetahuannya juga akan baik.

\section{Media Leaflet terhadap Pengetahuan Remaja Tentang Bahaya Narkoba.}

Hasil perhitungan dan statistic dengan menggunakan Uji Wilcoxon Signed Rank Test untuk mengetahui pengaruh media leaflet terhadap peningkatan pengetahuan menunjukkan pada tingkat kemaknaan $\mathrm{P}<0,05$ didapat nilai $\mathrm{p}=0,00$, yang berarti $\mathrm{H} 0$ gagal diterima. Berdasarkan penjelasan tersebut dapat diambil kesimpulan bahwa ada perbedaan yang signifikan, pengetahuan responden sebelum dan sesudah menggunakan media leaflet.

Pendidikan kesehatan sangat diperlukan untuk meningkatkan pengetahuan dan kemampuan seseorang melalui teknik praktik belajar atau instruksi secara individu untuk meningkatkan kesadaran kesehatan sehingga dengan sadar mau mengubah perilakunya menjadi sehat, langkah penting dalam pendidikan kesehatan adalah dengan membuat pesan yang disesuaikan dengan termasuk pemilihan media, disini peneliti menggunakan media leaflet untuk menyampaikan informasi yang dapat memberikan efek yang signifikan terhadap peningkatan pengetahuan (Sarwono, 2012)

Hasil penelitian Suiraoka \& Supariasa (2012) mengatakan bahwa kelebihan media leaflet adalah dapat disimpan lama, sasaran dapat menyesuaikan dan belajar mandiri, pengguna dapat melihat isinya saat santai, jangkauan sasaran lebih luas, dapat membantu media lain, dan isi dapat dicetak kembali.
Penelitian ini sejalan dengan penelitian Kurnia Azizah (2016) yang berjudul Efektivitas Layanan Media Informasi Leaflet Mengenai Penyalahgunaan Narkoba Terhadap Pergaulan Remaja di SMP Negeri 5 Yogyakarta. Penelitian tersebut menunjukkan bahwa ada pengaruh efektivitas media leaflet dengan pengetahuan remaja tentang narkoba dengan hasil rata-rata pengetahuan remaja meningkat.

Ketika setelah diberikan media leaflet terjadi peningkatan pengetahuan sebelum diberikan leaflet dan sesudah diberikan. Dapat dilihat dari hasil penelitian, pengetahuan yang sudah baik tapi belum keseluruhan menjadi lebih baik dalam menyeluruh, dari data tabel terlihat responden semua berpengetahuan baik. Oleh karena itu, media leaflet efektif dalam pemberian pendidikan kesehatan.

\section{KESIMPULAN}

Berdasarkan hasil penelitian tentang Pengaruh Media Leaflet Terhadap Peningkatan Pengetahuan Remaja Tentang Bahaya Narkoba di SMP Negeri 5 Banjarbaru Tahun 2019 terhadap 76 responden penulis akan menarik suatu kesimpulan dan memberi saran dari hasil penelitian yang telah dilaksankan, yaitu :

1. Pengetahuan responden Tentang Bahaya Narkoba sebelum diberikan media leaflet mayoritas dikategorikan berpengetahuan baik 72 responden $(94,7 \%)$.

2. Pengetahuan responden Tentang Bahaya Narkoba setelah diberikan media leaflet mayoritas dikategorikan berpengetahuan baik sebanyak 76 responden (100\%). 
Ada pengaruh media leaflet terhadap peningkatan pegetahuan remaja tentang bahaya narkoba yaitu terdapat peningkatan pengetahuan setelah diberikan media leaflet dengan $p$-value sig-0,00 $<0,05$ yang berarti $\mathrm{H} 0$ gagal diterima.

Selanjutnya, berdasarkan kesimpulan diatas, peneliti selanjutnya menyarankan beberapa hal sebagai berikut:

1. Untuk Responden

Mengoptimalkan pengetahuan responden tentang bahaya narkoba agar dimasa akan datang responden bisa mengantisipasi diri dan mencegah agar terhidar dari narkoba yang sangat berbahaya.

2. Untuk Pihak SMP Negeri 5 Banjarbaru

Mengoptimalkan pengetahuan pengajar atau staf di SMP Negeri 5 agar para pengajar dan staf bisa melakukan penyuluhan tentang bahaya narkoba tersebut.

\section{AKNOWLEDMENT}

Terima kasih kepada semua pihak yang telah banyak membantu suksesnya penelitian ini, terutama kepada SMPN 5 Banjarbaru dan jajarannya. Tidak lupa juga terima kasih kepada pimpinan STIKES Intan Martapura yang sudah sangat mendukung pelaksanaan kegiatan penelitian ini.

\section{DAFTAR PUSTAKA}

Annalia Wardhani. (2019). Hubungan Self Efficacy Dengan Penatalaksanaan Pencegahan Kekambuhan Hipertensi. Jurnal Kesehatan Suaka Insan 4 (2) 70-77

Azizah Kurnia. (2016). Efektivitas Layanan Media Informasi Leaflet Mengenai Penyalahgunaan Narkoba Terhadap Pergaulan Remaja di SMP Negeri 5 Yogyakarta.

BNN Prov Kal-Sel. (2018). Laporan Bulan januari - oktober BNN Banjarbaru Provinsi Kalimantan Selatan Tahun 2018.Banjarbaru: BNN Prov. Kalsel

Insana Maria. (2018). Gangguan Rasa Nyaman Pada Pasien Hipertensi. Jurnal Kesehatan Suaka Insan 3 (2) 1-9

Notoatmodjo, L. (2015). Metode Penelitian Kesehatan. Jakarta: Rineka Cipta

Purnama, Arif Putra. (2013). Efektivits Penggunaan Media Video dan Media Leaflet Terhadap Perubahan Pengetahuan dan Sikap Siswa Tentangf Bahaya Nafza di SMPN 3 Mojosong Byolali.

Sarwono. (2012). Psikologi Remaja. Jakarta : Pengantar Perilaku Manusia. Jakarta : EGC

Suryono. (2012). Penanggulangan Bahaya Narkoba : Media Informasi Dan Edukasi Peyalahgunaan Narkoba. Jakarta : Kemitraan Peduli Penanggulangan Bahaya Narkoba.

Suiraoka dan Supariasa, N. 2012. Media Pendidikan Kesehatan. Yogyakarta: Graha Ilmu 